\title{
Encouraging Innovation in Teen Pregnancy Prevention Programs
}

\author{
Kelly L. Wilson', Whitney R. Garney ${ }^{1}$, Christi N. Hays ${ }^{1}$, Jordan L. Nelon'1, Jennifer L. Farmer ${ }^{2}$, \\ Kenneth R. McLeroy ${ }^{2}$
}

${ }^{1}$ Department of Health and Kinesiology, Texas A\&M University, College Station, TX, USA

${ }^{2}$ Center for Community Health Development, School of Public Health, Texas A\&M University, College Station, TX, USA

Email: kwilson@tamu.edu, wrgarney@tamu.edu, Cnhays2011@tamu.edu, jlnelon@tamu.edu, jfarmer@sph.tamhsc.edu,

KMcLeroy@sph.tamhsc.edu

How to cite this paper: Wilson, K. L., Garney, W. R., Hays, C. N., Nelon, J. L., Farmer, J. L., \& McLeroy, K. R. (2017). Encouraging Innovation in Teen Pregnancy Prevention Programs. Creative Education, 8, 294-303.

https://doi.org/10.4236/ce.2017.82023

Received: December 17, 2016

Accepted: February 25, 2017

Published: February 28, 2017

Copyright $(9) 2017$ by authors and Scientific Research Publishing Inc. This work is licensed under the Creative Commons Attribution International License (CC BY 4.0).

http://creativecommons.org/licenses/by/4.0/

\begin{abstract}
While there is widespread support for implementing evidence-based interventions to improve adolescent health, health programs either become out dated and the participants are not engaged or new programs are needed for underserved populations. Innovation receives attention in health care and health systems. However, in health education the focus on innovation surrounds translating programs into practice; there is a lack of information on developing innovative programs which address disparities in teen pregnancy prevention. Given no guidelines exist to support the development of innovative programs in health, this skill is generally lacking and not widely used nor considered especially in content areas like teen pregnancy prevention. This paper discusses the gaps and opportunities for supporting and fostering innovation in adolescent health and teen pregnancy prevention programming.
\end{abstract}

\section{Keywords}

Innovation, Design, Program Development, Teen Pregnancy Prevention, Health Education

\section{Introduction}

Teen pregnancy is a frequently discussed social issue. Nationally, there is widespread support for evidence-based interventions to decrease a young person's risk of experiencing or causing an unintended pregnancy. Traditionally, sexual health programs have targeted individual behavior change and have been offered primarily in school and community settings (Farb \& Margolis, 2016). In order to reach the most at risk youth or underserved populations, new approaches and settings must be incorporated into the evidence-base. As a result, one important, 
emerging trend among funders is addressing current disparities in teen pregnancy prevention through developing innovative programs (US Department of Health and Human Services, Assistant Secretary for Health, Office of Adolescent Health [OAH], 2016C).

While innovation has received increasing attention in education (Huberman \& Miles, 2013), health (Leshner, Terry, Schultz, \& Liverman, 2013), and social sciences (Wandersman, Chien, \& Katz, 2012), much of the attention in innovation has focused on translating programs or best practices into new settings; thus, it focuses on adoption rather than intervention development. Healthcare settings frequently focus on creating new services or products that improve customer satisfaction and cost effectiveness of procedures (Free et al., 2013; Chaudoir, Dugan, \& Barr, 2013), but they neglect wide-scale replication or translation. Within the field of health education in the higher education setting, innovation has been used to flip classroom instructional models (Galway, Corbett, Takaro, Tairyan \& Frank, 2014), enhance instruction through game-based methods for training and education, and teach cultural competence to the emerging health workforce (Abdulmajed, Park \& Tekian, 2015; Neilsen, Noone, Voss \& Matthews, 2013). While working with youth and adolescents, innovation could be utilized to advance classroom or group-based instruction, enhance participants' comfort in the education environment, and improve uptake of health-related information. As the field of health education continues to expand its application, there is a lot to learn about innovation principles and how they can be used to develop new solutions for complex issues.

Current public health guidelines frequently promulgated to strengthen health and public health practice, and public health guidelines frequently outline requirements for systematic literature review (Moher et al., 2015), procedures for implementation and replication (Hoffmann, et al., 2014) and for standard expectations for efficacy, effectiveness and the ability to scale-up an intervention (Gottfredson et al., 2015). However, no guidelines exist to support the development of innovative programs. Therefore, innovative program design is generally lacking and not widely used nor considered.

The concept and process of program innovation provides an opportunity to overcome frequent disconnects between program characteristics and the intended target population's needs (Kasper \& Glohesy, 2008). The 2016 Evidence-Based Programs list highlights models that are often implemented within community and school settings and use a traditional classroom-based methodology to deliver teen pregnancy prevention efforts (OAH, 2016a; OAH, 2016b; Farb \& Margolis, 2016). Despite sexuality education standards (Future of Sex Education Initiative, 2012), promising programs and an evidence-based programs list, youth often lack access to sexuality-related instruction (Guttmacher Institute, 2010-2011; Lindberg, Maddow-Zimet, \& Boonstra, 2016). Existing programs utilize many of the teaching practices used in community and school settings and still adhere to models emphasizing the traditional classroom based methodologies to deliver the content. 
The purpose of this paper is to explore the current state of programs developed for populations at increased risk for unintended pregnancy, discuss how teen pregnancy prevention programs can be strengthened through innovations design and implementation setting, and examine how innovative programs can strengthen their effects on populations at greatest risk.

\section{Evidence Based Programs and Gaps in Teen Pregnancy Prevention}

In 2007, a review of programs designed to reduce adolescent sexual risk behaviors identified effective interventions which delayed sexual behaviors, increased contraceptive use, and reduced teen pregnancy (Kirby, 2007). Since that time, several sexual health programs have been identified as effective in reducing teen pregnancy, STIs, and associated sexual risk behaviors among specific target populations (OAH, 2016a; Maness \& Buhi, 2013). In support of a growing field to decrease teen and unplanned pregnancy, an evidence-based program list was established and supported by government entities such as the U.S. Department of Health and Human Services' Office of Adolescent Health (OAH), Administration for Children and Families (ACF), and the Centers for Disease Control and Prevention (CDC) (OAH, 2016a; OAH, 2016b).

Most of the programs on the federal Evidence-Based Programs list, were designed for implementation in middle and high schools, clinics, after school or community-based organizations, and specialized settings. Programs were designed with a number of approaches ranging from abstinence-based to sexual health education, youth development to programs designed for delivery in a clinical setting and various programs for special populations (OAH, 2016a; OAH, 2016b; Kappeler \& Farb, 2014). Further, many programs were based on population based approaches and designed to be implemented with an entire target population based on race, ethnicity, or other identifiable social characteristics, such as African Americans and Hispanic and/or Latinos $(\mathrm{OAH}$, 2015).

Evidence-based teen pregnancy programs are primarily designed to affect adolescent pregnancy risks and impact change at the individual-level and focused on the participants' characteristics such as knowledge, skills, attitudes, values, and individual access to resources (Goesling, Colman, Trenholm, Terzian \& Moore, 2014). As a result, they may not adequately address important contextual factors that contribute to adolescent pregnancy, such as stage of sexual career, relationships with partners, social norms within identifiable social groups, and systematic factors, such as availability and access to contraceptives (Douglas \& Fenton, 2013). It is suggested program developers should strengthen individually-oriented approaches to a more ecological and systemic approach that supports programs in a variety of new settings and populations and that include interventions and targets of change at multiple intervention levels, including interpersonal, organizational, community, policy, and system level changes. 


\section{Innovation in Health Education Programs}

Theories, frameworks, and models guide program planning and evaluation within the field of health education; however, limited guidance exists for innovative design and strategy or strategies during program development. The construct of innovation has historically focused on adoption and dissemination (Rogers, 1995; Wandersman et al., 2008; Wandersman, Imm, Chinman \& Kaftarian, 2000). For example, Diffusion of Innovations provides an understanding to how, why, and at what rate an innovation is distributed among groups. This theory includes elements related to an innovation's characteristics, characteristics of potential adopters, and characteristics of the social system that influence spread and adoption of an innovation. It is recognized the process of adoption is influenced by human capital, but also occurs within complex systems (Rogers, 1995). Additional frameworks have been adapted or developed to support the implementation and dissemination of health programs. For example, Wandersman created the Interactive Systems Framework as an aid to implement and disseminate program models. This framework allows for feedback among systems working together, which theoretically enables innovators to creatively develop and operationalize their teen pregnancy prevention programs (Wandersman et al., 2008; Lewis et al., 2012). Despite frameworks and models focused on the adoption process, there is a lack of focus on the practice of utilizing innovative design thinking and approaches during the planning and development of such programs.

The design and development of health education programs using innovative strategies can enhance the potential for success. Many innovations are generated by gathering insights from the intended target population(s), multiple perspectives, which includes empathizing and brainstorming to rapidly prototype ideas that are usable by others (Brown \& Wyatt, 2015, Kasper \& Glohesy, 2008). Creating new programs is not just about having an exciting idea; those that successfully navigate innovative design utilize a process that results in successful planning and development. Through an organized and systematic approach, program designers should spend time understanding the needs of their population, which will lead to program innovations with greater results and ultimately benefit more people over time (Kasper \& Glohesy, 2008).

\section{Fostering Innovation in Teen Pregnancy Prevention}

In 2010, the President's Teen Pregnancy Prevention Initiative was funded to support medically accurate and age-appropriate programs that reduce teen pregnancy and sexual risk related behaviors. This initiative is administered by the Office of Adolescent Health, with similar initiatives administered by Administration for Children and Families (ACF) and Centers for Disease Control and Prevention (CDC). In 2010-2014, OAH funded organizations to replicate and evaluate teen pregnancy prevention programs that have proven to be effective, or supported programs considered "promising" (Kappeler \& Farb, 2014). The early support of promising programs was an initial investment in advancing teen 
pregnancy prevention programs; however, given the ongoing gaps and disparities in existing evidence-based teen pregnancy prevention programs and approaches, two large scale projects were funded in 2015 to foster and support innovative approaches to teen pregnancy prevention (Kappeler \& Farb, 2014). One project was funded to focus on technology-based innovations in teen pregnancy prevention, the other project seeks to answer, "how can we foster innovation in teen pregnancy prevention programs that are innovative in design and approach to impact populations at greatest risk?"

Innovation has been utilized in the public sector for several decades and has common characteristics that can be utilized in teen pregnancy prevention. De Vries, Bekkers, and Tummers (2015) conducted a systematic literature review and reported on the types and goals of innovation. In addition to identifying the context in which innovation was applied and defined, multiple types of innovation were identified, including: process innovation, product or service innovation, governance innovation, and conceptual innovation. Understanding the different types or dimensions of innovation is important because innovation characteristics can impact the focus as well as the adoption of the process or program. Related to the teen pregnancy prevention initiative, process innovation and product or service innovation would describe many of the initiatives identified in the literature as innovative. However, governance innovation and conceptual innovation could expand the approach and potential impact of teen pregnancy prevention initiatives.

\section{Innovation and Teen Pregnancy Prevention Programs}

Innovation design is a trend in health care and health systems and has been used to improve social impacts on health (Brown \& Wyatt, 2015). Despite growing trends of utilizing innovation design to develop products for use by target populations, significant opportunities exist to understand its use in planning and implementation of health-related prevention programs, particularly in areas like teen pregnancy prevention.

While the field of teen pregnancy prevention has advanced scientific understanding of implementing and replicating evidence-based programs (Koh, 2014; Margolis \& Roper, 2014), gaps in meeting target population needs, delivering programs in various settings, utilizing different levels of intervention, and offering non-traditional programs still exist. Fostering and supporting innovation is necessary to keep up with the advances in human behavior and technology, thus the question, "how can the field advance programs that are innovative and engage the target population and impact adolescent pregnancy or birth rates" still remains.

Although we ask the question about advancing programs through innovation, the concept of cultivating innovation in teen pregnancy prevention initiatives has been supported. Teen pregnancy prevention programs described as innovative incorporated life planning and goal setting (Barbee, Cunningham, van Zyl, Antle, \& Langley, 2016), cultural relevance and sensitivity (Jenner et al., 2016; 
Abe, Barker, Chan \& Eucogco, 2016), technology (Kaufman, Schwinn, Black, Keane \& Big Crow, 2016; Markham, et al., 2012; Bull et al., 2016, Downs et al., 2004), and holistic youth development approaches targeting adolescent risk behaviors (Piotrowski \& Hedeker, 2016). Lessons learned related to the future implementation of these programs include the cost and time of program implementation, training of facilitators and staff, using hybrid approaches to tailor activities for participants, and incorporating culturally relevant stories/examples and values (Barbee, Cunningham, van Zyl, Antle, \& Langley, 2016; Abe, Barker, Chan \& Eucogco, 2016; Bull et al., 2016; Piotrowski \& Hedeker, 2016; Downs et al., 2004). However, counter to the concept of rapidly capturing and prototyping ideas to programs (Wilson \& Rosenberg, 1988), teen pregnancy prevention models have been slow in their uptake by organizations and facilitators outside government funded grantees (Rolleri, Wilson, Paluzzi \& Sedivy, 2008). While these approaches address content gaps in existing programs, a review of emerging promising programs indicates a majority of these emerging teen pregnancy prevention programs will still be traditional in design and approach.

Some have called for innovative thinking and design as a tool to be used and applied to teen pregnancy prevention programs. In 2015 the Department of Health and Human Services' Office of Adolescent Health frames innovative programs "broadly as new or promising approaches, strategies, interventions, or curricula, informed by scientific theory or empirical evidence that may lead to or have the potential to result in a substantial reduction in teen pregnancy rates, sexual transmitted infection (STIs) rates, and associated sexual risk behaviors" (Office of Adolescent Health, 2015). Within the literature, Rolleri, Wilson, Paluzzi, and Sedivy (2008) use the identification of tangible tools which lead to a reduction in adolescent sexual risk-taking behavior as a form of innovation, but they do not specify needs related to program planning, implementation, or delivery methods.

\section{Concluding Comments}

Program designers strive to create programs which address multifaceted issues and factors influencing teen sexual health and pregnancy rates. Development of innovative programs is a challenge because it takes time to rigorously test and evaluate programs so they can be deemed effective. Guidelines and expectations are clearly outlined to identify an acceptable study of a program; however, respective guidelines to drive innovative program development is lacking. Given that few existing programs are what would be called creative and engaging to the target audience and environments in innovative ways, new programs are needed or adaptations to existing programs need to occur.

The need has emerged for programs in teen pregnancy prevention to be developed innovatively and with multiple approaches. To begin incorporating innovative design into programs, a safe space for creative ideas to emerge is needed and the intermediaries funded to enhance and support innovation in teen pregnancy prevention poised themselves to provide such environment. This 
will increase the possibility that programs in the future look different from those on the evidence based list and currently in existence. While changes in effectiveness may not be noticeable right away, we can see the participants are more engaged in the program and still affect the rates of teen pregnancy.

This article contends innovation has a place in adolescent health program planning beyond its current application of program adoption and dissemination. The teen pregnancy prevention initiative offers one step towards understanding how innovative design strategies and multi-level approaches can advance the field and how our team can identify innovative initiatives in the next few years. Perhaps a new way of thinking can provide opportunities and insights for designers which will aid facilitators and participants. The challenge is establishing a creative and engaging teen pregnancy prevention program for the users which is different from what already exists, and is new and innovative for the field, then testing and disseminating for adoption before the program loses its innovative characteristics.

\section{Acknowledgements}

This manuscript is made possible by Grant Number AH-TP2-15-001 from the HHS Office of Adolescent Health. Contents are solely the responsibility of the Texas A\&M University and do not necessarily represent the official views of the Department of Health and Human Services or the Office of Adolescent Health.

\section{References}

Abdulmajed, H., Park, Y. S., \& Tekian, A. (2015). Assessment of Educational Games for Health Professions: A Systematic Review of Trends and Outcomes. Medical Teacher, 37, S27-S32. https://doi.org/10.3109/0142159X.2015.1006609

Abe, Y. Y., Barker, L. T., Chan, V., \& Eucogco, J. (2016). Culturally Responsive Adolescent Pregnancy and Sexually Transmitted Infection Prevention Program for Middle School Students in Hawaii. American Journal of Public Health, 106, S110-S116. https://doi.org/10.2105/AJPH.2016.303395

Barbee, A. P., Cunningham, M. R., van Zyl, M. A., Antle, B. F., \& Langley, C. N. (2016). Impact of Two Adolescent Pregnancy Prevention Interventions on Risky Sexual Behavior: A Three-Arm Cluster Randomized Control Trial. American Journal of Public Health, 106, S85-S90. https://doi.org/10.2105/AJPH.2016.303429

Brown, T., \& Wyatt, J. (2015). Design Thinking for Social Innovation. Annual Review of Policy Design, 3, 1-10.

Bull, S. S., Devine, S., Schmiege, S. J., Pickard, L., Campbell, J., \& Shlay, J. C. (2016). Text Messaging, Teen Outreach Program, and Sexual Health Behavior: A Cluster Randomized Trial. American Journal of Public Health, 106, S117-S124. https://doi.org/10.2105/AJPH.2016.303363

Chaudoir, S. R., Dugan, A. G., \& Barr, C. H. (2013). Measuring Factors Affecting Implementation of Health Innovations: A Systematic Review of Structural, Organizational, Provider, Patient, and Innovation Level Measures. Implementation Science, 8, 22. https://doi.org/10.1186/1748-5908-8-22

Department of Health and Human Services, Office of the Assistant Secretary for Health, Office of Adolescent Health (2016c) Supporting and Enabling Early Innovation to Ad- 
vance Adolescent Health and Prevent Teen Pregnancy: Overview of Funded Grant Projects.

https://www.hhs.gov/ash/oah/oah-initiatives/tpp_program/assets/tier-2a-descriptions.

pdf

Douglas Jr., J. M., \& Fenton, K. A. (2013). Understanding Sexual Health and Its Role in More Effective Prevention Programs. Public Health Reports, 128, 1-4. https://doi.org/10.1177/00333549131282S101

Downs, J. S., Murray, P. J., Bruine de Bruin, W., Penrose, J., Palmgren, C., \& Fischhoff, B. (2004). Interactive Video Behavioral Intervention to Reduce Adolescent Females' STD Risk: A Randomized Controlled Trial. Social Science \& Medicine, 59, 1561-1572. https://doi.org/10.1016/j.socscimed.2004.01.032

Farb, A. F., \& Margolis, A. L. (2016). The Teen Pregnancy Prevention Program (2010-2015): Synthesis of Impact Findings. American Journal of Public Health, 106, S9-S15. https://doi.org/10.2105/AJPH.2016.303367

Free, C., Phillips, G., Watson, L., Galli, L., Felix, L., Edwards, P., Haines, A. et al. (2013). The Effectiveness of Mobile-Health Technologies to Improve Health Care Service Delivery Processes: A Systematic Review and Meta-Analysis. PLoS Medicine, 10, e1001363. https://doi.org/10.1371/journal.pmed.1001363

Future of Sex Education Initiative (2012). National Sexuality Education Standards: Core Content and Skills, $K-12$.

Galway, L. P., Corbett, K. K., Takaro, T. K., Tairyan, K., \& Frank, E. (2014). A Novel Integration of Online and Flipped Classroom Instructional Models in Public Health Higher Education. BMC Medical Education, 14, 181. https://doi.org/10.1186/1472-6920-14-181

Goesling, B., Colman, S., Trenholm, C., Terzian, M., \& Moore, K. (2014). Programs to Reduce Teen Pregnancy, Sexually Transmitted Infections, and Associated Sexual Risk Behaviors: A Systematic Review. Journal of Adolescent Health, 54, 499-507. https://doi.org/10.1016/j.jadohealth.2013.12.004

Gottfredson, D. C., Cook, T. D., Gardner, F. E., Gorman-Smith, D., Howe, G. W., Sandler, I. N., \& Zafft, K. M. (2015). Standards of Evidence for Efficacy, Effectiveness, and Scale-Up Research in Prevention Science: Next Generation. Prevention Science, 16, 893-926. https://doi.org/10.1007/s11121-015-0555-x

Guttmacher Institute (2010-2011). State Policies in Brief. Sex and STI/HIV Education. New York: Guttmacher Institute.

Hoffmann, T. C., Glasziou, P. P., Boutron, I., Milne, R., Perera, R., Moher, D., Lamb, S. E. et al. (2014). Better Reporting of Interventions: Template for Intervention Description and Replication (TIDieR) Checklist and Guide. BMJ, 348, g1687. https://doi.org/10.1136/bmj.g1687

Huberman, A. M., \& Miles, M. B. (2013). Innovation up Close: How School Improvement Works. Berlin: Springer.

Jenner, E., Jenner, L. W., Walsh, S., Demby, H., Gregory, A., \& Davis, E. (2016). Impact of an Intervention Designed to Reduce Sexual Health Risk Behaviors of African American Adolescents: Results of a Randomized Controlled Trial. American Journal of Public Health, 106, S78-S84. https://doi.org/10.2105/AJPH.2016.303291

Kappeler, E., \& Farb, A. (2014). Historical Context for the Creation of the Office of Adolescent Health and the Teen Pregnancy Prevention Program. Journal of Adolescent Health, 54, S3-S9. https://doi.org/10.1016/j.jadohealth.2013.11.020

Kasper, G., \& Glohesy, S. (2008). Intentional Innovation: How Getting More Systematic about Innovation Could Improve Philanthropy and Increase Social Impact (Rep.). WK 
Kellogg Foundation Website.

https://www.wkkf.org/resource-directory/resource/2008/09/intentional-innovation-full -report

Kaufman, C. E., Schwinn, T. M., Black, K., Keane, E. M., \& Big Crow, C. K. (2016). The Promise of Technology to Advance Rigorous Evaluation of Adolescent Pregnancy Prevention Programs in American Indian and Alaska Native Tribal Communities.

Kirby, D. (2007). Emerging Answers 2007: Research Findings on Programs to Reduce Teen Pregnancy and Sexually Transmitted Diseases. Washington DC: National Campaign to Prevent Teen and Unplanned Pregnancy.

Koh, H. (2014). The Teen Pregnancy Prevention Program: An Evidence-Based Public Health Program Model. Journal of Adolescent Health, 54, S1-S2. https://doi.org/10.1016/j.jadohealth.2013.12.031

Leshner, A. I., Terry, S. F., Schultz, A. M., \& Liverman, C. T. (2013). Committee to Review the Clinical and Translational Science Awards Program at the National Center for Advancing Translational Sciences. Board on Health Sciences Policy, Institute of Medicine, the CTSA Program at NIH: Opportunities for Advancing Clinical and Translational Research.

Lewis, K., Lesesne, C., Zahniser, S., Wilson, M., Desiderio, G., Wandersman, A., \& Green, D. (2012). Developing a Prevention Synthesis and Translation System to Promote Science-Based Approaches to Teen Pregnancy, HIV and STI Prevention. American Journal of Community Psychology, 50, 553-571.

https://doi.org/10.1007/s10464-012-9510-1

Lindberg, L., Maddow-Zimet, I., \& Boonstra, H. (2016). Changes in Adolescents' Receipt of Sex Education, 2006-2013. Journal of Adolescent Health, 58, 621-627. https://doi.org/10.1016/j.jadohealth.2016.02.004

Margolis, A. L., \& Roper, A. Y. (2014). Practical Experience from the Office of Adolescent Health's Large Scale Implementation of an Evidence-Based Teen Pregnancy Prevention Program. Journal of Adolescent Health, 54, S10-S14. https://doi.org/10.1016/j.jadohealth.2013.11.026

Markham, C. M., Tortolero, S. R., Peskin, M. F., Shegog, R., Thiel, M., Baumler, E. R., Robin, L. et al. (2012). Sexual Risk Avoidance and Sexual Risk Reduction Interventions for Middle School Youth: A Randomized Controlled Trial. Journal of Adolescent Health, 50, 279-288. https://doi.org/10.1016/j.jadohealth.2011.07.010

Moher, D., Shamseer, L., Clarke, M., Ghersi, D., Liberati, A., Petticrew, M., Shekelle, P., \& Stewart, L. A. (2015). Preferred Reporting Items for Systematic Review and Meta-Analysis Protocols (PRISMA-P) 2015 Statement. Systematic Reviews, 4, 1-9. https://doi.org/10.1186/2046-4053-4-1

Piotrowski, Z. H., \& Hedeker, D. (2016). Evaluation of the Be the Exception Sixth-Grade Program in Rural Communities to Delay the Onset of Sexual Behavior. American Journal of Public Health, 106, S132-S139. https://doi.org/10.2105/AJPH.2016.303438

Rogers, E. M. (1995). Diffusion of Innovations (4th ed.). New York: Free Press.

Rolleri, L. A., Wilson, M. M., Paluzzi, P. A., \& Sedivy, V. J. (2008). Building Capacity of State Adolescent Pregnancy Prevention Coalitions to Implement Science-Based Approaches. American Journal of Community Psychology, 41, 225-234. https://doi.org/10.1007/s10464-008-9177-9

US Department of Health and Human Services, Office of the Assistant Secretary for Health, Office of Adolescent Health (2015). Supporting and Enabling Early Innovation to Advance Adolescent Health and Prevent Teen Pregnancy (Tier 2A). DHHS Announcement No. AH-TP2-15-001, Washington DC: US Government Printing Office. https://www.hhs.gov/ash/oah/grants/2015\%20FOAs/tier2a-foafile.pdf 
US Department of Health and Human Services, Office of the Assistant Secretary for Health, Office of Adolescent Health (2016a). Evidence-Based Teen Pregnancy Prevention Programs at a Glance.

https://www.hhs.gov/ash/oah/oah-initiatives/teen_pregnancy/training/Assests/ebp-tabl e.pdf

US Department of Health and Human Services, Office of the Assistant Secretary for Health, Office of Adolescent Health (2016b). TPP Resource Center: Evidence-Based Programs. https://www.hhs.gov/ash/oah/oah-initiatives/teen_pregnancy/db/

Wandersman, A., Chien, V. H., \& Katz, J. (2012). Toward an Evidence-Based System for Innovation Support for Implementing Innovations with Quality: Tools, Training, Technical Assistance, and Quality Assurance/Quality Improvement. American Journal of Community Psychology, 50, 445-459. https://doi.org/10.1007/s10464-012-9509-7

Wandersman, A., Duffy, J., Flaspohler, P., Noonan, R., Lubell, K., Stillman, L., Saul, J. et al. (2008). Bridging the Gap between Prevention Research and Practice: The Interactive Systems Framework for Dissemination and Implementation. American Journal of Community Psychology, 41, 171-181. https://doi.org/10.1007/s10464-008-9174-Z

Wandersman, A., Imm, P., Chinman, M., \& Kaftarian, S. (2000). Getting to Outcomes: A Results-Based Approach to Accountability. Evaluation and Program Planning, 23, 389-395. https://doi.org/10.1016/S0149-7189(00)00028-8

Wilson, J., \& Rosenberg, D. (1988). Rapid Prototyping for User Interface Design. In M. Helander (Ed.), Handbook of Human-Computer Interaction (pp. 859-875). Amsterdam: North-Holland. https://doi.org/10.1016/B978-0-444-70536-5.50044-0

Submit or recommend next manuscript to SCIRP and we will provide best service for you:

Accepting pre-submission inquiries through Email, Facebook, LinkedIn, Twitter, etc. A wide selection of journals (inclusive of 9 subjects, more than 200 journals)

Providing 24-hour high-quality service

User-friendly online submission system

Fair and swift peer-review system

Efficient typesetting and proofreading procedure

Display of the result of downloads and visits, as well as the number of cited articles

Maximum dissemination of your research work

Submit your manuscript at: http://papersubmission.scirp.org/

Or contact ce@scirp.org 